\title{
Effect of the "Godber" Staffing Structure on the Anaesthetic Service
}

\author{
T. H. TAYLOR, ${ }^{*}$ M.B., B.S., F.F.A.R.C.S. ; A. M. C. JENNINGS, $†$ M.B., B.CHIR., F.F.A.R.c.s. \\ D. LEIVERS, $\ddagger$ B.M., B.CHIR., F.F.A.R.C.S.
}

British Medical fournal, 1970, 3, 39-42

\section{Introduction}

Several reports have been published in the past few years which have examined the medical staffing structure within the National Health Service (Ministry of Health and Department of Health for Scotland, 1960; Ministry of Health, 1967; Ministry of Health and the Scottish Home and Health Department, 1968; Department of Health and Social Security and the Department of Health for Scotland, 1969) and the training of doctors aspiring to the highest posts within that service (Royal Commission on Medical Education, 1968; Joint Consultants Committee, 1969). The training needs have also been examined by the various specialist organizations and the royal colleges (Joint Committee on Higher Surgical Training, 1968; Faculty of Anaesthetists, Royal College of Surgeons of England, 1969), but in these reports we have been unable to find any firm reference to the most important factor. This is, of course, the work-load with which these doctors, both specialist and trainee, are expected to deal. As we have said elsewhere (Taylor et al., 1969a), this is surely the base from which to start such discussions. The collecting of operational research data is time-consuming but perfectly feasible. We have already published one such study of the work-load of junior anaesthetists (Nightingale and Taylor, 1966) and a detailed study of the emergency anaesthetic work of three hospital groups (Taylor et al., 1969b, 1969c, 1969d, 1969e, 1969f). At present we are studying the routine work of the same hospitals. Detailed analysis of the data has not been completed, but the crude figures from part of the material are available for this paper (A. M. C. Jennings et al., unpublished data).

For the national statistics we have referred to the Ministry staffing prospects for England and Wales (Health Trends, 1969), and for the numbers of hospital beds to the Hospital Year Book (1968). Reference is also made to the provision of H.M. (67) 26 and 27 (National Health Service, 1967a, 1967b). For the purposes of assessing the work-load one session has been assumed to be three and a half hours (National Health Service, 1967c). Though, of course, we do not believe that the work of any doctor must be bound to rigid hours, it seems reasonable that such a unit should be used in planning the staffing structure of an anaesthetic service. This gives a nominal working week of $38 \frac{1}{2}$ hours for a full-time appointment. In accordance with modern management science techniques, we have used our data to construct statistical models of the work situation and have experimented with these to produce probable answers. We do not claim that the models represent any given situation but that they indicate the trend of the work-load and give some idea of the range of variability.

\footnotetext{
* Consultant Anaesthetist, the London Hospital, London E.1.

† Consultant Anaesthetist, Northampton General Hospital, Northampton.

. Registrar Anaesthetist, the London Hospital, London E.1.
}

In staffing a service according to these methods individual doctors would still find overwhelming work-loads on occasions and lighter loads at other times, but staff so allocated are more likely to be able to cope adequately with such variations. Provision should, however, always be made continuously to monitor the work-load in any given hospital group so that any major alterations, either up or down, can be dealt with by varying the number of staff and the duties they perform (Taylor et al., 1969a).

\section{Available Staff}

The first assumption is that the normal professional life of an anaesthetist is 40 years. We feel that 32 of these years will be spent in a "definitive" post (we wish to avoid the use of the words "consultant" and "specialist") and eight in a "training" post (including preregistration posts) (Faculty of Anaesthetists, Royal College of Surgeons of England, 1969). We also assume that the numbers of U.K. graduates in these two groups are in balance (Department of Health and Social Security and the Department of Health for Scotland, 1969). This means that one trainee is in a post for four doctors in permanent posts. The number of trainees may well be somewhat higher because of (1) wastage, (2) other specialists (including family doctors) who wish to acquire some anaesthetic knowledge, and (3) overseas graduates who are acquiring higher training in the specialty.

No one would wish many doctors to "fall off the training ladder," and probably with proper career guidance and good selection for adequate training programmes the wastage would be small. The number of doctors training for other specialties temporarily in anaesthesia is likely to be balanced by anaesthetists who are in training posts for other specialties. Indeed the Faculty of Anaesthetists, Royal College of Surgeons of England (1969), emphasized the desirability of this. Similarly it is to be hoped that the number of overseas graduates will not be allowed to rise excessively. It is therefore unlikely that these factors would increase the number of doctors in training by more than twice that required, and indeed undesirable that they should. If they did so the equilibrium of the static situation that we are considering would be altered and the result would be a prolongation of the training period in relation to the definitive period. Hence we arrive at a "Godber staffing unit" in anaesthetics which will consist of four trained doctors in definitive posts, one U.K. graduate in training, and one overseas graduate (or other specialist temporarily in anaesthetics). Even if our assumptions are incorrect, however, the effect on the subsequent arguments can easily be deduced from the material presented.

\section{Definitive Posts}

The figures for 1968 show that the sessional commitments of the 1,150 consultants in appointments amounted to 
952.5 whole-time equivalents. Thus each consultant's work represents 9.1 sessions a week, and we shall assume nine a week throughout. Hence each of these anaesthetists is available for 468 sessions in one year, though this number is reduced by annual leave (54 sessions) (National Health Service, 1967c), sickness (14 if the national average is taken) (Nightingale and Taylor, 1966), and study leave (20 sessions) (National Health Service, 1967b). This last will become increasingly important if appointments to these posts are made at an early age, for the standards of the 1970s are unlikely to be applicable to the early years of the twenty-first century. The anaesthetists in definitive posts are therefore available for 380 sessions a year-that is, a Godber unit provides 1,520 available sessions in this category a year.

\section{Training Posts}

Here the anaesthetist is nominally employed full-time-that is, 11 sessions a week, or 572 a year. This is reduced by annual leave (47 sessions, allowing for an average of 4.3 weeks' holiday a year in all grades) (National Health Service, 1967c), sickness (14 sessions) (Nightingale and Taylor, 1966), study leave ( 60 sessions - that is, three terms of 10 weeks, one day a week (National Health Service, 1967b), and minimum offduty time (72 sessions-that is, one half-day per working week and alternate Saturday mornings) (National Health Service, 1967a). In addition, leave has to be granted for examinations and interviews, which may amount to nine sessions a year. Thus a trainee anaesthetist is likely to be available for 370 sessions a year. The anaesthetic training of these doctors, however, is not wholly catered for by day release. In some part apprenticeship to a senior colleague must continue so as to provide practical teaching. The number of sessions available is therefore reduced still further, but this may be offset by the value of such an arrangement in staffing emergency services, as we have suggested elsewhere. (Taylor et al., 1969e). Thus a Godber unit will produce something less than 740 working sessions by trainees.

\section{Present Staffing of the Two Groups}

It has become traditional to state that the "teaching hospitals" contain $20 \%$ of the staff and $6 \%$ of the National Health Service beds in England and Wales and to infer that a reserve of underworked staff is available in them. Nevertheless, certainly in anaesthetics these figures are greatly misleading. Many of the 468,295 beds (Hospital Year Book, 1968) involved do not generate anaesthetic demands to any degree greater than the population at large does. In fact, 311,209 scarcely contribute to the demand at all (these include those used for infectious and chest diseases, geriatric and chronic psychiatric cases, subnormality, pre-convalescence, convalescence, and others). Of the remainder 132,850 are in non-teaching hospitals and 24,236 are in teaching hospitals. The former are staffed by 1,793.3 whole-time equivalent anaesthetists in all grades and the latter by 553. This is 1.35 whole-time equivalents per 100 beds in the non-teaching hospitals and 2.28 per 100 in the teaching hospitals.

Our data on emergency work (Taylor et al., 1969b, 1969c, 1969d, 1969e, 1969f) and routine work (A. M. C. Jennings et al., unpublished data) show the mean case duration in the teaching hospital to be roughly double that in the regional hospital. This is due mainly to the increased complexity of the work in the former, and obviously this complexity extends to the preoperative investigations and postoperative care of such cases. The same complexity accounts for the somewhat fewer operations per bed per annum and the increased volume of investigatory work requiring anaesthesia outside the theatres. It seems, therefore, that at least in anaesthetics there is no great inequity in the distribution of the total work force, and certainly there is no great body of under-used manpower in the teaching hospitals.

\section{Staff Ratios}

The Northampton Division of Anaesthesia serves 750 acute beds. The staff now amount to 12.4 whole-time equivalents (an increase of 1.7 since September 1968)-that is, 1.65 per 100 beds (1.47 in 1968). This is within the range for non-teaching hospitals. The present staff consist of five consultants, one senior hospital medical officer, one senior registrar, three registrars, and three senior house-officers-that is, the ratio of definitive to training posts is six to seven. In the Godber plan probably the ratio of definitive to training posts should be four to two. This would imply eight definitive posts and four training posts to give similar whole-time equivalents. (This is, in fact, rather less, since we have shown that consultants are mostly not full-time.)

The London Hospital Department of Anaesthesia serves 1,472 beds, of which 140 are psychiatric. The staff for these amount to 27.4 whole-time equivalents-that is, 2.0 per 100 beds. We have ignored the psychiatric beds (and also the 1,000 such beds at Northampton) because of the major distortions such bed numbers produce. These chronic beds produce little more work than the population at large does, except for the electric convulsion therapy sessions, which we have allowed for. This staff ratio is rather lower than the national average for a teaching hospital. Of these equivalents three are university academic staff who bear their part of the clinical work in the hospital, especially in intensive care and cardiac surgery. The staff consist of 10 consultants, 4 senior registrars, 1 lecturer, 9 registrars, and 6 senior house-officers. This is a ratio of definitive staff to trainee staff of 11 to 19 . In the Godber plan the ratio would be four to two-that is 20 in definitive posts and 10 trainees. This number of anaesthetists is slightly higher than at present ( 2.6 whole-time equivalents). In view of the large volume of specialized work; such as thoracic, cardiac, vascular, and neurosurgical, which is a major requirement for training anaesthetists, the ratio at this hospital might in fact be altered, but it is doubtful whether it should ever be more than one to one.

\section{Work-load}

We now refer to the observed work-load in two areas where we have carried out surveys. In the emergency work (Taylor et al., 1969b, 1969c, 1969d, 1969e, 1969f) this was complete and collected in late 1967. Nevertheless, the general principles are sufficiently accurate for this analysis. The routine theatre work is being analysed (A. M. C. Jennings et al., unpublished data), and non-theatre work-load has been deduced from known examples. This last consists of routine work, such as that in the $x$-ray, cardiac, dental, and outpatient departments, and somewhat more urgent work from intensive care units.

\section{Northampton General Hospital and Group}

The length of operating-lists was 170 minutes, (S.D. 68 minutes, S.E. 5 minutes). That is to say there is a $95 \%$ confidence that the mean list length is between 160 and 180 minutes. All the outside commitments appeared to have similar means and variance.

The anaesthetic work schedule provides for 62 lists plus two sessions of electric convulsion therapy. During a fourweek period 225 out of a possible 248 lists took place. Of the 64 regular weekly commitments 7 are regularly and con- 
sistently under-used. In some of these a function is served by staffing outlying beds in a former sanatorium 10 miles (16 km.) away. It would be possible to cut out about eight lists which are under-used and increase the length of the other lists, to, say, 190-200 minutes. This probably results in bed wastage and inconvenience to the other staff which we have not studied. It would seem therefore that the routine anaesthetic work in this group could be covered by about 58 sessions a week, all of a length equivalent to one session. This includes provision for work outside theatres, in the $x$-ray department, etc. In addition there is a need to provide adequate emergency cover. We have shown that one person is almost always inadequate for this purpose and therefore two are required (Taylor et al., 1969e, 1969f). One of these would be available to double up on routine lists and thus acquire some training from a senior colleague as suggested above. The anaesthetic department also has a considerable degree of resoonsibility for a five-bedded intensive therapy unit. This again is mostly emergency rather than routine work. With additional aid available from emergency staff, the work can be dealt with in 10 sessions a week over the period Monday to Friday.

Thus the sessional oommitments amount to 58 for routine list work and 10 for intensive therapy, making 68 in all. In addition emergency cover has to be provided over and above this amounting to 30-50 additional sessions a week. These extra sessions will provide some opportunity to train juniors by the apprenticeship method.

Now from our previous calculations two Godber units of staff would provide 4,520 sessions of work per annum, of which 1,480 were performed by trainees, though for part of their time they should be accompanying a senior colleague. This gives a weekly contribution of about 58 definitive sessions and 28 trainee, a total of 86 . The observed need is for 68 routine plus at least 30 for emergency commitments-that is, 98. In fact, at times the emergency staff will probably undertake routine commitments, to the detriment of the emergency service, but, even so, the overall service is likely to be short of staff at most times.

The total numbers available fit. Allowing for leave and absence to be spread evenly through the year (a difficult thing with illness and school holidays) there should always be 10 or 11 people available. Allowing for day release of some of the juniors not more than eight regular commitments would be entered into at once if any margin were to be available for emergencies. This again is rather less than at present. The emergency duties could be managed with a one-in-four rota of all grades with a trainee on first call and probably resident and definitive staff on second and third calls. This would give adequate cover, but again because of annual leave and sickness would actually be more like a one-in-three rota for all grades in the absence of locumtenents.

\section{London Hospital Group}

The length of half-day operating lists was 223 minutes (S.D. 102 minutes, S.E. 10 minutes). That is to say, there is a $95 \%$ confidence that the mean list length is between 203 and 243 minutes. Similarly, the all-day lists (mainly neurosurgical, thoracic surgical, and cardiovascular surgical) had a mean of 390 minutes, with a standard deviation of 165 minutes and a standard error of 24 minutes, giving a $95 \%$ confidence of the list finishing within $342-438$ minutes. Nearly all the outside commitments finished within the stipulated sessional time.

The week's work schedule provides for 125 regular commitments of routine work. This consists of 94 operating sessions in three hospitals and 31 outside sessions (including electric convulsion therapy) in outpatient and $x$-ray departments and the dental school. This "outside" work component is large because of the dental school but also because of the investigations required by the neurosurgical, renal, and cardiovascular surgical departments. During a four-week period 347 of the 376 sessions occurred (some lists equal two sessions) and all the outside cornmitments. Three of the lists were regularly slightly under-used, but the outside commitments were not. So the regular weekly commitment is for 125 sessions of work. In addition the emergency commitment requires at least three free anaesthetists, a work-load of 60-100 sessions a week. The intensive therapy unit also requires routine work as well as help from the emergency team, probably amounting to 15 sessions a week.

The sessional commitments therefore amount to 125 for routine work, plus 15 for intensive care, and the allowance for emergency cover of 60 sessions-200 in all.

From our previous calculations five Godber units of staff would provide 7,600 sessions of work per annum by definitive grades and 3,700 sessions of work by trainees. This gives a weekly contribution of 146 definitive sessions and 71 trainee sessions, a total of 217. The observed need is for something of the order of 200 sessions. It should, however, be observed that the eight part-time consultants average only 5.4 sessions a week at present (not the nine sessions as calculated earlier), and the part-time staff as well as the academic staff have duties in teaching and research for which no time has been allocated in this analysis. In addition the number of Godber units that we have used gives a total of 2.6 whole-time equivalents more staff than now employed.

The matching of the total numbers for the emergency cover could be made by placing four definitive staff and two trainees on duty each night, an increase of one anaesthetist over the present situation, and giving a one-in-five rota. Because of the total number of staff involved (30), this would at all times result in a rota no better than one in four and often worse. The service is likely to be very much worse unless the definitive staff as well as the trainees are resident. Travel in London is always difficult and the group has responsibility for three maternity units in different hospitals, one of which is $7 \frac{1}{2}$ miles $(12 \mathrm{~km}$.) away, and also for an annexe 21 miles (34 km.) away (Taylor et al., 1969c).

\section{Financial Considerations}

The increase in definitive posts in Northampton is $2(33 \%)$ and at the London Hospital $10(100 \%)$. In addition at the latter hospital the sessional equivalents would rise from 81 to between 180 and 220, a rather greater percentage rise. The increased cost of these sessions gives, in fact, rather less actual work than the money at present expended on junior staff, not only because of the higher salaries but because of the greater leave entitlement and the greater commitments of a consultant in such matters as committees, appointment committees, research, and teaching.

A further consideration is the implication for private practice, which nearly all the present staff of both groups engage in. This will be affected by the Godber staffing plan in two ways. Firstly, the total available, which cannot be expected to increase greatly in the present social and political atmosphere, will have to be shared among more definitive staff; secondly, that staff will have a greater immediate commitment to hospital work, especially in the emergency services, and will therefore find it more difficult to be available for private work. For this reason perhaps a direct item for service payment, especially for emergency work, should be negotiated. In this respect we agree with Freeman (1969) in his analysis of the orthopaedic services.

\section{Conclusions}

Consideration of the actual anaesthetic work-load of two large hospital groups, one a district hospital in the Midlands 
and the other a large London undergraduate teaching group, shows that staffing arrangements similar to the Godber working party's could be made to work. Probably the services offered would be somewhat worse than those at present. All short or badly used sessions would have to be cut out in the interests of efficiency.

We have been careful to use the words "definitive" grades for the permanent staff and "trainee" for the junior staff. We believe that the latter should be a progressive grade from first-year to seventh-year anaesthetists. The former will consist of the present full-time and part-time consultants, with a few (221.5 whole-time equivalents out of a total of 1,641 wholetime) other grades, such as senior hospital medical officer, medical assistant, junior hospital medical officer, and para 94 appointments. We see no reason why all the definitive appointments need be fully trained consultant anaesthetists in the present mode. There are several sessions which could usefully be done by a sub-consultant grade, whether they be hospital practitioner or a "failed" consultant. The only problem is that these people would be entitled to remuneration on the scale of a principal in general practice-with the inevitable problem of the salary of a consultant.

Another difficulty concerns the facilities available for work. Any department staffed along these lines requires a centralized office with secretarial help. (Taylor et al., 1969f). In addition we can see no way of adequately covering units in widely scattered buildings. The provision of large hospitals with no outlying annexes is essential if such a method of staffing is to be achieved. Though this would ease the problem of the emergency cover, a part-time consultant living at home, will not with the best will in the world, be able to provide so satisfactory or immediate a service as a full-time registrar has done in the past. We do not believe that this system would provide a great incentive to recruitment to the specialty, nor do we think it would prove attractive to general practitioners or married women, who are usually unable to give adequate emergency cover.

The plan could be implemented only by increasing the total number of anaesthetists in the definitive grades by $33 \%$ or more in the non-teaching hospitals. This would be greater in more scattered groups. In the teaching hospitals the increase would be correspondingly greater, perhaps about $100 \%$ or more if sessional commitments were taken into account. Hence probably $300-400$ more definitive grade anaesthetists would be required. We have not taken into account further increases necessitated by population growth or rises in work-load from the progress of medicine. The output from the senior registrar grade is 50 per annum, and even now some of these posts remain unfilled.

The conclusion must be that this staffing plan will fail, partly because of lack of suitable definitive staff but also because of inadequate existing buildings and facilities. It is this increase of definitive staff, however, which has allowed the Department of Health to assert that the number of trainees would not diminish in the manpower projection to 1978. The situation described above is the static one when the Godber staffing arrangements are implemented. Until that has been achieved the injection of the required extra number of trainees into the system to increase the eventual output of fully trained anaesthetists will mean that all trainee recruits will be accommodated without limitation. The difficulties arise, firstly, in sustaining the level of recruitment for this purpose and, secondly, in the inevitable cut-back in training posts that will be necessary when adequate staffing ratios have finally been achieved.

Many people have helped us in discussions about this paper. We would especially like to mention the house-governor of the London Hospital for his help. Our data are processed by the Operational Research Unit of the London Hospital.

\section{REFERENCES}

Department of Health and Social Security and the Department of Health for Scotland (1969). The Responsibilities of the Consultant Grade. London, H.M.S.O.

Faculty of Anaesthetists, Royal College of Surgeons of England (1969) Newsletter, October, appendix I.

Freeman M. A. R. (1969). British Medical fournal, 4, 612

Health Trends, 1969, 1, No. 2, p. 23.

Hospital Year Book, 1968, p. 400.

Joint Committee on Higher Surgical Training (1968). Report. London, Royal College of Surgeons of England.

Joint Consultants Committee (1969). British Medical fournal, 1, Suppl., p. 75.

Ministry of Health (1967). First Report of the Foint Working Party on the Organisation of Medical Work in Hospitals. London H.M.S.O.

Ministry of Health and Department of Health for Scotland (1960). Medical Staffing Structure in the Hospital Service. London, H.M.S.O

Ministry of Health and the Scottish Home and Health Department (1968). Foint Final Report. Negotiations Between the Health Departments and the Representatives of the National Health Service Hospital Doctors and Dentists 1966-68, appendix I. London, Ministry of Health.

National Health Service (1967a). Minimum Time Off-duty for Funior and Intermediate Grades of Hospital Medical and Dental Staff. H.M. (67) 26. London, Ministry of Health.

National Health Service (1967b). Professional and Study Leave for Medical and Dental Staff in the Hospital Service. H.M. (67) 27. London, Ministry of Health.

National Health Service (1967c. Terms and Conditions of Service of Hospital Medical and Dental Staff (England and Wales) and Headquarters Medical Staff of Regional Hospital Boards (England and Wales), section 5. London, Ministry of Health.

Nightingale, D. A., and Taylor, T. H. (1966). British Medical fournal, 1, 1218.

Royal Commission on Medical Education (1968). Report 1965-1968. Cmnd. 3569. London, H.M.S.O.

Taylor, T. H., Jennings, A. M. C., and Nightingale, D. A. (1969a). "The Applications of the Techniques of Management Science to Anaesthesia." Annual Meeting, Association of Anaesthetists, Anaesthesia."

Taylor, T. H., et al. (1969b). British Fournal of Anaesthesia, 41, 70.

Taylor, T. H., et al. (1969c). British fournal of Anaesthesia, 41, 76.

Taylor, T. H., et al. (1969d). British fournal of Anaesthesia, 41, 167.

Taylor, T. H., et al. (1969e). British fournal of Anaesthesia, 41, 357.

Taylor, T. H., et al. (1969f). British fournal of Anaesthesia, 41, 362. 